\title{
Gaz ziemny jako zabezpieczenie wierzytelności we włoskim systemie podziemnych magazynów gazu
}

\author{
Natural gas as a security in the Italian \\ underground gas storages system \\ Zuzanna Brocka
}

E-mail: zbrocka@ slbius.eu; nr ORCID: 0000-0001-9672-4940

\begin{abstract}
Streszczenie
Artykuł przedstawia włoskie przepisy dotyczące wykorzystania gazu ziemnego złożonego w podziemnych magazynach gazu (PMG) do zabezpieczenia majątkowego wierzytelności pieniężnych. Zagadnienie to wzbudza żywe zainteresowanie włoskiej doktryny prawnej, ponieważ wymaga dostosowania tradycyjnego pojęcia zastawu, które ma swoje korzenie w prawie rzymskim, do specyfiki funkcjonowania nowoczesnych rynków gazu. Analiza teoretyczna ma ponadto istotne znaczenie praktyczne dla operatorów sektora energetycznego działających na włoskim rynku PMG, który stanowi drugi rynek pojemności magazynowych w Unii Europejskiej, gdyż taka forma zabezpieczenia wierzytelności może mieć istotny wpływ na ich sytuację finansową przez zmniejszenie kosztów dostępu do kredytu.
\end{abstract}

Słowa kluczowe: gaz ziemny, podziemne magazyny gazu, zabezpieczenie wierzytelności, zastaw, zastaw rejestrowy

\section{Summary}

The article presents Italian regulations on the use of natural gas deposited in underground gas storages (UGS) as financial security of monetary claims. This issue arouses a keen interest in the Italian legal doctrine because it requires to adapt the traditional concept of pledge, which has its roots in Roman law, to the specifics of functioning of modern gas markets. The theoretical analysis also has important practical significance for energy sector operators active in the Italian UGS market, which is the second largest market of storage capacity in the European Union (EU), as this form of securing debt may have a significant impact on their financial situation by reducing the cost of access to credit.

Key words: natural gas, underground gas storages, securities, pledge, registered pledge

JEL: K12, K20

Str. 26-34

\section{Bibliografia}

Barbiera, L. (2010). Responsabilita patrimoniale. Disposizioni generali, Milano: Giuffré.

Bortone, P. (2006). Pegno irregolare con funzione di garanzia e deposito a scopo di garanzia. W: G. Cassano (red.). Garanzie personali e reali. Torino: UTET.

Concas, A. (2012). Il diritto commerciale dalle origini ad oggi e la sua disciplina nel codice civile. https://www.diritto.it/il-dirittocommerciale-dalle--origini-ad-oggi-e-la-sua-disciplina-nel-codice-civile/ (10.02.19).

De Angelis, L., Brocka, Z. (2003). Gas Storage Licenses in the new Liberalisation Context. International Energy Law \& Taxation Review, 26(4), 129-132.

Figaszewska, I., Jasienowicz, A., Muras, Z. (2001). Zasady dostępu stron trzecich do sieci energetycznych. Biuletyn URE, (2). https://www.ci-re.pl/publikacje/zdstdse.pdf (16.10.2018).

Guarino, A. (2001). Diritto Privato Romano. Napoli: Jovene. 
Kaliski, M., Janusz, P., Szurlej, A. (2010). Podziemne magazyny gazu jako element krajowego systemu gazowego. Nafta-Gaz, (5), 325-332.

Komisja Europejska. (2014). Italy. https://ec.europa. eu/energy/sites/ener/files/documents/2014_countryreports_italy.pdf (14.05.2019).

Maccario, F. (2018). Appunti per un progetto di riforma delle garanzie di credito. http://questionegiustizia.it/articolo/appunti-per-unprogetto-di-ri- forma-delle-garanzie-di-credito_29-05-2018.php (16.10.2018).

Ministero dello Sviluppo Economico. (2017). Italy's National Energy $\quad$ Strategy 2017. https://www.mise.gov.it/images/stories/documenti/BROCHU-RE_ENG_SEN.PDF (14.05.2019).

Monteforte, P. (2018). Il patto marciano, Iurisprudentia. it, (10). http://www.iurisprudentia.it/il-patto-marciano/ (14.05.2019).

Roman, A. (1998). Umowa o przepadek na tle ustawy o zastawie rejestrowym i rejestrze zastawów. Rejent, 8(9), 88-104.

Romboli, R. (red.). (2015). Manuale di diritto costituzionale italiano ed europeo (t. 2). Le fonti del diritto, $i$ diritti e i doveri costituzionali costituzionali e gli organi di garanzia giurisdizionale. Torino: Giappichelli.

Rozwadowski, W. (1992). Prawo rzymskie. Zarys wykładu wraz z wyborem źródet. Poznań: Ars Boni et Aequi.

Rubertelli, V. (2016). Il patto marciano. https://www.federnotizie. it/il-patto-marciano/ (14.05.2019).

Silipo, A. (2014). Il pegno irregolare sul gas naturale depositato in stoccaggio. Osservatorio Del Diritto Civile E Commerciale, (2), 249282.

Silvi, M. Q. (2011). Dimensioni giuridiche dello stoccaggio del gas naturale. W: M. Renna (red.). Infrastrutture di stoccaggio e quote di mercato del gas naturale (1-24). Milano: Vita \& Pensiero.

Torrente, A., Schlesinger, P. (2010). Manuale di Diritto Privato. Milano: Giuffre.

Vittoria, D. (1990). Pegno Irregolare. W: Enciclopedia giuridica Treccani (1-8). Roma: Istituto della Enciclopedia Italiana.

\section{Akty prawne}

Decreto legge 3 maggio 2016, n. 59 convertito con modificazioni dalla legge 30 giugno 2016, n. 119 recante disposizioni urgenti in materia di procedure esecutive e concorsuali, nonché a favore degli investitori in banche in liquidazione (GURI nr $153 \mathrm{z}$ 2.07.2016 r.).

Decreto legislativo z 23.05.2000 r. nr 164 Attuazione della direttiva n. 98/30/CE recante norme comuni per il mercato interno del gas naturale, a norma dell'articolo 14 della legge 17 maggio 1999, n. 144. (GURI nr 142 z 20.06.2000 r.).

Dyrektywa Parlamentu Europejskiego i Rady 2009/73/WE z 13.07.2009 r. dotycząca wspólnych zasad rynku wewnętrznego gazu ziemnego i uchylająca dyrektywę 2003/55/WE (Dz. Urz. UE L 211, s. 94, ze zm.).

Legge z 26.04.1974 r. nr 170 Stoccaggio di gas naturale in giacimenti di idrocarburi.

\section{Orzeczenia}

Wyrok Cassazione civile z 24.05.2004 r., n. 100000.

Wyrok Cassazione civile z 6.12.2006 r., n. 26154.

Wyrok Cassazione civile z 9.05.2013 r., n. 10986.

Wyrok Cassazione civile z 28.01.2015 r., n. 1625.

Wyrok Cassazione civile, z 8.08.2016 r., n. 16618.

Wyrok Consiglio di Stato, Sekcja VI, z 11.09.2014 r., n. 4629/2014.

Wyrok TAR Lombardia, Sekcja Trzecia, z 13.12.2012 r., n. 3030.

\section{Źródla internetowe}

http://unmig.sviluppoeconomico.gov.it/unmig/stoccaggio/info/cosa.asp (14.05.2019).

http://www.bankpedia.org/index.php/it/121-italian/p/21565-pegno-irregolare (14.05.2019).

https://igs.eu (14.08.2018).

https://www.arera.it/it/docs/14/423-14.htm (14.05.2019).

https://www.arera.it/it/inglese/index.htm (14.05.2019).

https://www.autorita.energia.it/allegati/docs/11/045-11arg.pdf (14.05.2019).

https://www.edisonstoccaggio.it/en (14.05.2019).

https://www.gie.eu/dmdocuments/20150729\%20-\%20GIE\%20Investment\%20WG\%20-

\%20Paper\%20on\%20Investment\%20Database\%20-\%20v15\%20-\%20FINAL\%20 (CLEAN).pdf (14.05.2019).

http://www.snam.it/en/about-us/company-structure/stogit/index.html (14.05.2019). 